\section{Invitational Synthesis Paper}

The Editorial Board of the Journal of Range Management invited James E. Ellis and David M. Swift to prepare this synthesis paper in recognition of their many, valuable contributions to understanding of the ecology of grazing systems. Their work is characterized by a high level of imagination, by a steady commitment to thoroughness, and by distilled, clear thinking.

JIM ELLIS took undergraduate work in animal husbandry at the University of Missouri and also obtained his Master of Science degree there studying wildlife biology. In 1970, he received his Ph.D. in Zoology at the University of California at Davis, where he was a National Institute of Health trainee in systems ecology. Shortly thereafter, he held a National Science Foundation postdoctoral fellowship at the University of Bristol working on systems analysis of mammalian social systems. He joined the Natural Resource Ecology Laboratory of Colorado State University as a Research Ecologist in 1971. He is currently the Associate Director of the Laboratory. Jim has enjoyed immense success in developing research programs; during the last decade he directed or played a major role in 12 successful proposals, collectively exceeding three million dollars in support. He has published extensively, with most of his work focussing on processes regulating grazing systems. Jim has served as a consultant to the U.S. Senate, as well as the government of Saudi Arabia and the Norwegian Agency for International Development. His most recent project uses a systems approach to understand the controls on stability and persistence of a pastoral ecosystem in East Africa.

DAVE SWIFT studied forest botany as an undergraduate at the the New York State College of Forestry and received a master's degree in watershed resources at Colorado State University. In 1985 he earned his Ph.D. in Animal Science at Colorado State University. Since 1970 he has been a member of the staff of the Natural Resource Ecology Laboratory where he now serves as a

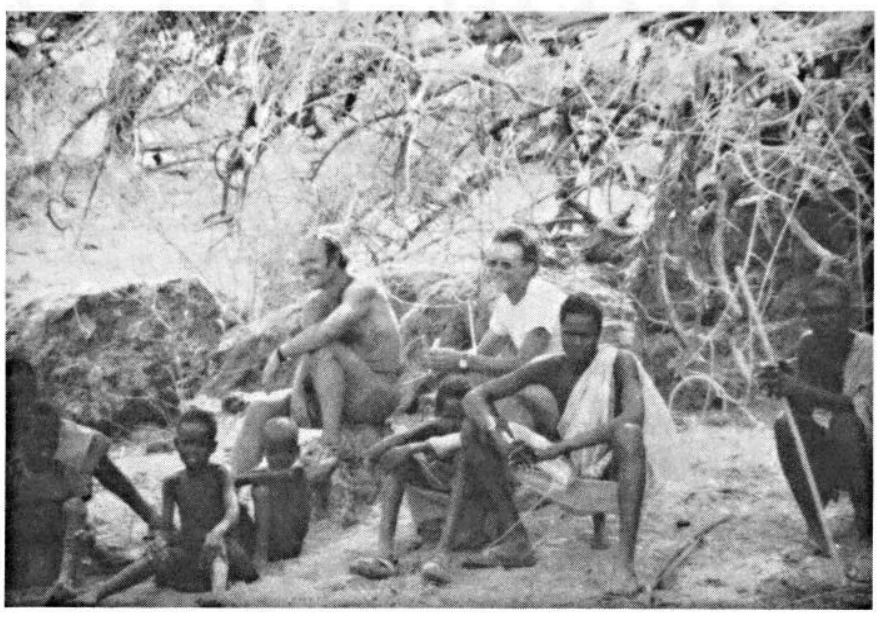

Jim Ellis and Dave Swift in Turkana District, Kenya.

Research Scientist. Dave has deep expertise in simulation of ecological systems. He has worked on models investigating energy and nitrogen balance in ruminants, control of diapause in grasshoppers, carrying capacity of elk winter range, effects of sulfur dioxide on grassland ecosystems, influences of grazing on primary production, and the nutritional benefits of herding. He frequently contributes to the applied as well as the theoretical ecological literature. Dave teaches courses in ruminant nutrition in the Range Science and Wildlife Biology departments at Colorado State University and has supervised the research of many masters and doctoral students. He is widely admired by those who have had the good fortune to study with him. His recent work has taken him to East Africa, Pakistan, and the People's Republic of China.

\title{
Stability of African pastoral ecosystems: Alternate para- digms and implications for development
}

\author{
JAMES E. ELLIS AND DAVID M. SWIFT
}

\begin{abstract}
African pastoral ecosystems have been studied with the assumptions that these ecosystems are potentially stable (equilibrial) systems which become destabilized by overstocking and overgrazing. Development policy in these regions has focused on internal alterations of system structure, with the goals of restoring equilibrium and increasing productivity. Nine years of ecosystem-level research in northern Kenya presents a view of pastoral ecosystems that are non-equilibrial but persistent, with system dynamics affected more by abiotic than biotic controls. Development practices that fail to recognize these dynamics may result in increased deprivation and failure. Pastoral ecosystems may be better supported by development policies that build on and facilitate the traditional pastoral strategies rather than constrain them.
\end{abstract}

Key Words: pastoral ecosystems, equilibrial ecosystems, nonequilibrial ecosystems, pastoral development

Authors are Associate Director and Senior Research Scientist, Natural Resource Ecology Laboratory, Colorado State University, Fort Collins, Colorado 80523, (303) 491-1643; Senior Research Scientist, Natural Resource Ecology Laboratory, and Associate Professor, Department of Range Science, Colorado State University, Fort Collins, Colorado 80523, (303) 491-1981.

\section{Perceptions of Pastoral Ecosystems}

Our view of the world, or our perception of any system, has a great deal of influence on how we go about dealing with that system. Believing that illness is caused by spirits leads to very different sorts of treatments than the perception that viruses or bacteria may be the cause. Likewise, our perception of how particular ecological systems operate determines the approaches that we advocate in attempting to modify or manipulate those ecosystems. For example, one school of thought held that unusually high concentrations of elephants were responsible for the wide-spread destruction of dry woodlands in many areas of east and central Africa (Beuchner and Dawkins 1961, Glover 1963, Laws 1970). An alternative hypothesis proposed that elephants and trees were locked in a stable limit-cycle in which elephant populations expanded at the expense of tree populations. Ultimately the loss of woodlands would cause reductions in elephant populations while woodlands would begin to recover, initiating a new cycle (Caughley 1976). The general perception of destructive elephant-tree interactions led to some large-scale programs of elephant "con- 
trol" in an effort to preserve woodlands. However, later work suggested that climate change, varying water tables, or combinations of herbivores, fire, and climate changes were responsible for the decline of woodlands. These results showed that elephant control programs were, in some cases, a needless slaughter of a scarce species (Western 1973, Sinclair and Norton-Griffiths 1979, Pellew 1983, Dublin 1987).

In scientific parlance the elephant-tree interaction was perceived in terms of a particular paradigm; that paradigm influenced the structure of scientific discourse, the types of analyses and models used, and the kinds of management solutions applied to related problems. Alterations in management practices occurred when the dominant paradigm was questioned and another proposed. Such changes in scientific paradigms often promote the use of new models, different analytical approaches, and new solution regimes (Kuhn 1970).

We believe that the time is ripe to examine the paradigms which govern our thinking about African pastoral ecosystems. Discussions of these pastoral ecosystems usually revolve around problems of low productivity, overstocking, overgrazing, drought, range deterioration, dying livestock, starving people, and so on. In essence, the current paradigm focuses on pastoralism as a maladaptive and destructive system of exploitation. However, years of intervention into pastoral systems, by governments and development agencies, have failed to relieve the perceived problems; in fact, development has sometimes rendered the target population and its ecosystem somewhat worse off than before the intervention (Helland 1980, Swift 1977, Sanford 1983, Swift and Maliki, 1984). This lack of success has been so pervasive that some research organizations and major funding agencies have essentially given up on pastoralists and arid lands in Africa and are investing their resources elsewhere (ILCA 1987). It is possible that some intervention failures could be the result of technical incompetence on the part of development experts or intransigence on the part of pastoralists. However, it seems unlikely that experts are always technically incompetent or pastoralists always intransigent; the near universal failure of pastoral development suggests that something more fundamental is amiss. Universal failure would be expected if invalid paradigms underlie the development interventions.

Two sorts of inquiries are needed to assess the validity of the dominant pastoral paradigm and the models and interventions which follow therefrom. First, it is necessary to identify the dominant paradigm, the assumptions on which it is based, and their implications. Secondly, the paradigm needs to be tested against extant observations and empirical data. Do the observed dynamics fit the dominant paradigm? If not, the paradigm obviously needs to be altered to provide a more realistic model of pastoral ecosystems from which better intervention and management procedures would hopefully derive.

In this paper we propose that the dominant paradigm of pastoral systems is based on assumptions (1) that African pastoral ecosystems are potentially stable (equilibrial) systems; (2) that these potentially stable systems are frequently destabilized by improper use on the part of pastoralists; and (3) that alterations of system structure (reducing livestock numbers, changing land-tenure patterns, etc.) are needed to return these systems to an equilibrial and more productive state. We then provide evidence from our own work (1) that stable equilibria are not achievable in many pastoral ecosystems, although long-term persistence is; (2) that interventions aimed at achieving stability in non-equilibrial systems are likely to be irrelevant at best or disruptive and destructive at worst; and (3) that successful interventions will be designed to accommodate system dynamic variation rather than aimed at maintaining equilibrial conditions.

\section{The Dominant Paradigm: Pastoral Degradation of Equilibrial Ecosystems}

There are at least 3 separate but interrelated perceptions of pastoralists and their ecosystems in the literature. The work of early ethnographers tended to picture traditional pastoralists in a rather romantic light, i.e., self-reliant nomads, moving freely, living off the land, while defying governments and settled agriculturalists (Evans-Pritchard 1940, Spencer 1973, Jacobs 1965). This perception seems also to have incorporated the idea, at least implicitly, that pastoralists lived in some sort of balance with their natural environment if not with their neighbors; pastoral systems were not identified with environmental degradation.

The idea that pastoralists do not achieve a balance with their environment but routinely overstock and overgraze, is an old one (Stebbings 1935), but was stated most forcefully and coherently by Brown (1971), the Chief Agriculturalist of colonial Kenya, and more recently by Lamprey (1983). Brown's viewpoint arose no doubt from his own experiences, but also incorporated the concept of the irrationality of pastoral management practices first posed by Herskovits (1926), whose "cattle complex"hypothesis spawned the view that accumulation of vast numbers of livestock was an irrational pastoral tradition, ingrained in the social system; a practice clearly incompatible with good environmental management. Brown identified a different sort of irrationality; he asserted that pastoralists were engaged in dairy operations under environmental conditions much more suitable for meat production and he suggested that these dairy operations tended to be very inefficient in terms of milk produced per unit of forage available. He then presented a numerical analysis of pastoral subsistence needs based on inefficient milk production and used this to substantiate the case for obligatory overstocking, overgrazing, and environmental destruction by pastoralists.

Lamprey, in contrast, pointed out that pastoral management is adaptive and rational from the perspective of human survival, but does not incorporate environmental conservation as a management objective (1983). Further, Lamprey's incisive ecological perspective brought some important assumptions into the open which are often held implicitly, but seldom stated. There is, in this view, the potential for density-dependent equilibria between herbivores and vegetation in the regions of East Africa occupied by pastoralists and such equilibria are frequently achieved in natural ecosystems, not inhabited by man. Lamprey reasoned that overstocking by pastoralists causes departures from these equilibrial conditions and rangeland degradation. Clearly, continuing degradation of the environment would eventually lead to extinction of pastoralists, but this has not occurred over the thousands of years of pastoral occupation of Africa because, "Either they could move on from the degraded lands into new territories, or they could adapt their pastoral practices to increasingly marginal conditions (for instance, by herding camels instead of cattle) and remain where they were" (Lamprey 1983, p. 664).

Thus the pastoral paradigm materializes: pastoral systems are potentially stable systems but departures from equilibrial conditions necessarily follow from the inefficiency of pastoral resource exploitation and the resultant need to overstock the ecosystem. This environmentally destructive pattern has not led to extinction, however, because new regions were exploited while the degraded ones presumably recovered (this might now be considered a patchdynamic equilibrium), or because alternate equilibrial states were possible (when a system was degraded by cattle it could still be utilized by camels or goats); i.e., these systems contain multiple stable points (Noy-Meir 1975).

The final element of the dominant paradigm proposes that in many cases development has exacerbated degradation in pastoral ecosystems. Veterinary care and reductions in tribal raiding are said to have released livestock populations from former densitydependent constraints, while curtailment of nomadism, losses of grazing lands to agriculture, security problems, and the settlement of some pastoralists have combined to reduce the area of rangeland available while herds are on the increase (Lusigi 1981, Lamprey and Yussuf 1981, Lamprey 1983). Overstocking and overgrazing 
have intensified while the reductions in rangeland area have removed the possiblity of achieving patch-dynamic equilibria. Resulting acceleration of degradation is hypothesized to be causing wide-spread shifts from cattle to camels in northern East Africa (Stiles 1983); while vegetation removal by livestock in the Sahel is believed to have increased soil surface albedo, leading to reductions in rainfall and rapid desertification (Charney et al. 1974, Sinclair and Fryxell 1985). To summarize, the dominant paradigm of pastoral ecosystem dynamics is based on perceptions that:

- Pastoralism is basically an inefficient and therefore environmentally destructive resource exploitation strategy.

- The ecosystems occupied by pastoralists have the capacity to support stable (equilibrial) populations of herbivores, but pastoral strategies necessarily lead to overstocking and tend to move the system away from the potential equilibrium conditions.

- Pastoralists have avoided large-scale extinctions by moving to new areas after degrading previously occupied environments or by changing strategies to accommodate the new but somewhat degraded environmental state.

- Modernization has made things worse by reducing the potential for large-scale movement and by removing density-dependent constraints on livestock populations (Fig. 1).

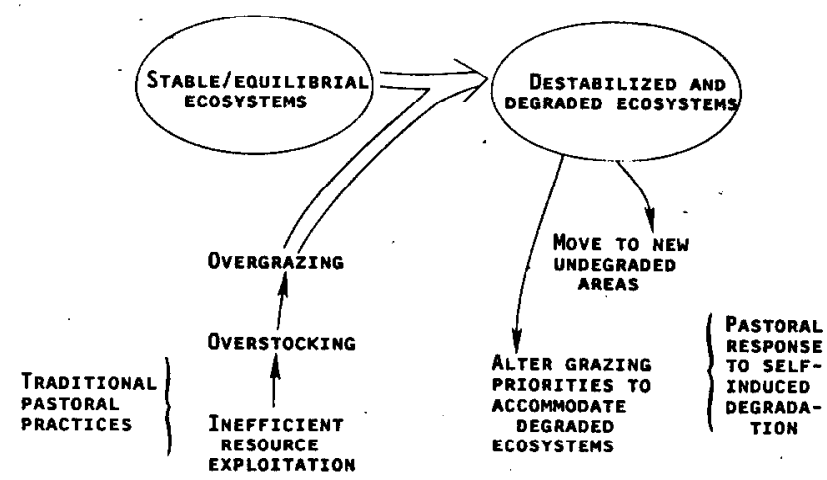

Fig. 1. The equilibrial paradigm of pastoral ecosystem dynamies.

\section{Implications of the Equilibrial Paradigm}

A similar perception of pastoral systems has been termed the "mainstream view" because it has dominated attitudes toward pastoralists and shaped pastoral development policy (Sandford 1983). Some of the major consequences which Sandford attributed to the mainstream view include the assumption that whatever pastoralists are doing is inappropriate and therefore range management programs aimed at reducing presumed degradation should be applied universally and rapidly. Likewise changes in land-tenure systems and existing institutions are assumed to be desirable and are therefore undertaken without consideration of what may be useful or valuable in the existing systems.

We think that the key assumption in the equilibrial paradigm has an even more fundamental impact on development policy than the mainstream view. The paradigm assumes that the ecosystems occupied by pastoralists generally function as equilibrial systems which are regulated by density-dependent feed-back controls; however, pastoralists override these feed-back controls to the detriment of themselves and their ecosystems. If this assumption is accepted, it is logical to reason that internal alterations in system structure can correct the imbalances and restore the system to equilibrial conditions. The most obvious adjustments to make are those involving the number of livestock per unit area. Hence two types of development procedures follow: reduction of stocking rates and alteration of land-tenure systems. Destocking is a very direct means of altering system structure, but it is hard to sell to pastoralists. Alteration of land-tenure has the advantage of less immediate and direct impacts on pastoralists and it also may have a certain appeal to some local planners or officials. The assumption is that some form of privatization will alleviate the imbalances supposedly induced by communal grazing. This is the viewpoint expressed in Hardin's 'tragedy of the commons' concept (Hardin 1968) as applied to pastoral systems. Group ranches, grazing blocks, grazing cooperatives, etc., are all schemes aimed at attaching groups of pastoralists to specific tracts of land which will presumably induce better management practices (Helland 1980, Oxby 1982). Implicit in the strategy is the premise that the tracts of land have the capacity to support stable, balanced populations of livestock and people if only good management prevails, i.e., equilibrial conditions are attainable (Fig. 2). The results of interventions

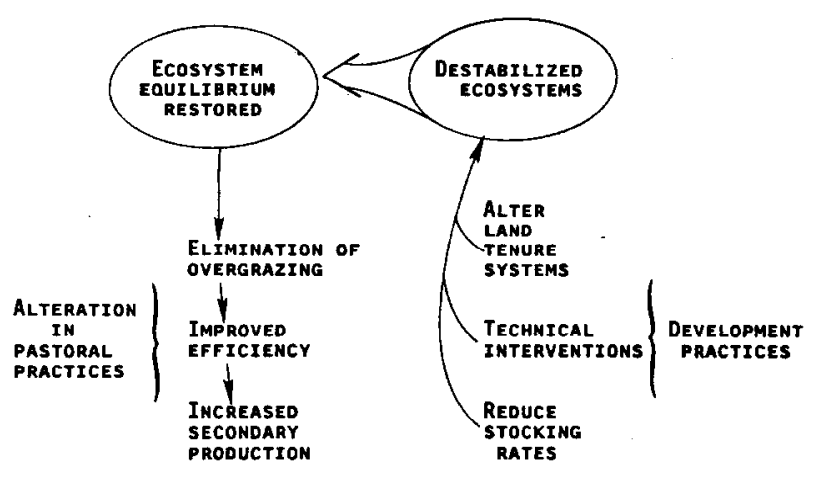

Fig. 2. Development practices and expected results based on the equilibrial paradizm.

and schemes based on these assumptions are not encouraging. They include disruption of pastoral societies and ecosystems and the retreat of development agencies from the arid and semi-arid lands of Africa (Helland 1980, Swift and Maliki 1984, ILCA 1987).

\section{Some Theoretical Considerations}

The idea that there is a balance of nature has always had great appeal to scientists, naturalists, and others. When the concept is stated in more analytical terms, it generally is accepted to mean that natural systems exist in some sort of homeostatic state, and that this state is maintained by interactions among the components of the system. The concept thus implies that the dominant type of system interaction is negative feed-back control of rate processes which maintain the system in a dynamic equilibrial state or within some limited domain of attraction. The antithetical view of natural system dynamics emphasizes the role of external control mechanisms, i.e., drivers, which are not subject to feed-back control from within the system. When system dynamics are dominated by external forces, the opportunity for the development of feed-back control is much reduced and the persistence of the system depends upon the development of other sorts of stabilizing mechanisms. These varying perceptions of natural system dynamics have given rise to famous scientific debates such as the density-dependent versus density-independent population control controversy (Nicholson 1958, Nicholson and Bailey 1935).

While these contrasting views of system dynamics are both now recognized as legitimate models of biological reality (Noy-Meir 1979/80, Wiens 1984), the concept that systems operate in a homeostatic fashion, based on equilibrial dynamics, has had by far the more pervasive. role in ecological thought. The ideas that communities are structured by competitive interactions and that evolution proceeds through a continuous process of adaptive "fine tuning", are based on an equilibrial view of system dynamics. In addition, the development of the concept of ecological stability and the analysis of the stability properties of ecological models proceeded from an assumption of equilibrial conditions (Lotka 1925, Volterra 1928, Rosenzwieg and MacArthur 1963). The equilibrial 
assumption, its implications for the competitive structuring of communities, and its validity in mathematical analyses, have been questioned (Wiens 1977, 1984, Caswell 1978, Connell and Sousa 1983); however, it remains a powerful concept in both field and mathematical assessments of population, community, and ecosystem dynamics. Clearly then, we should not be terribly surprised to find that equilibrial assumptions dominate our perceptions of pastoral ecosystems.

A major challenge to the equilibrial assumption was posed by Wiens, who after several years of field research on avian communities in arid and semi-arid environments, concluded that equilibrial conditions occurred only occasionally in these environments. He asserted that abiotic controls regulated bird populations in arid ecosystems and that since equilibrial conditions (those required for competitive interactions to develop) were seldom attained, the role of competition in shaping these communities was minimal (Wiens 1977). He extended these conclusions to propose that ecosystems exist along a gradient from equilibrial conditions where biotic interactions structure communities to non-equilibrial conditions where abiotic controls determine system structure and dynamics (Wiens 1984). This scheme has been further elaborated by DeAngelis and Waterhouse (1987), based on their review of model analyses of ecological stability. They propose that the spectrum of potential system behaviors centers on the concept of stable equilibrial systems, but that systems frequently fail to demonstrate equilibrial behavior due either to the disruptive effects of stochastic elements (such as abiotic controls) or due to instabilities induced by strong internal feed-backs. Strong feed-back or overconnectedness is exemplified where herbivores or predators over-exploit their food resources, resulting in departures from equilibrium points as proposed for the case of overgrazing by pastoralists. When strong feed-backs are accompanied by time-lags, stable-limit cycles may result. This is the dynamic suggested to explain the interdependent interactions between elephants and trees (Caughley 1976).

The question posed by DeAngelis and Waterhouse (1987) (and many theoretical modelers before them), focuses on how natural systems manage to persist in the face of pervasive destabilizing forces. Their resolution of the question is based on the operation of a number of different mechanisms incorporated into theoretical models to stabilize model performance. The crucial point is that different sorts of stabilizing mechanisms are required to ameliorate the effects of different destabilizing forces. Where destabilization results from strong stochastic forces, such as abiotic perturbations, persistence may be maintained by the introduction of compensatory mechanisms or by increasing the spatial scale of the model ecosystem. Where instability is caused by strong biotic interactions, stability may be regained by the introduction of disturbances which influence either resource or consumer density, or by incorporating mechanisms which reduce the strength of system interactions, e.g., interference, inefficiency, etc. Thus, the specific mechanisms employed in attempting to stabilize model ecosystem performance depend upon what one perceives as the critical destabilizing force. Although this analysis focuses on model ecosystems, it provides some important insights into the different ways in which real ecosystems may persist under the influence of potentially destabilizing controls and interactions (Fig. 3).

The implications for the persistence of African pastoral ecosystems are clear. If these are potentially equilibrial systems, controlled mainly by strong biotic interactions, then destabilizations and degradation may, in fact, be caused by overstocking and strong biotic coupling and feed-back from livestock to plants. This is a basic presumption of the dominant paradigm. Appropriate stabilizing procedures under these conditions would indeed involve fine-tuning the interaction between plants and livestock through such means as destocking and land privatization, provided these procedures actually reduced consumer density relative to vegetation resources. In other words, the currently applied development practices may be well-suited to correcting internally induced

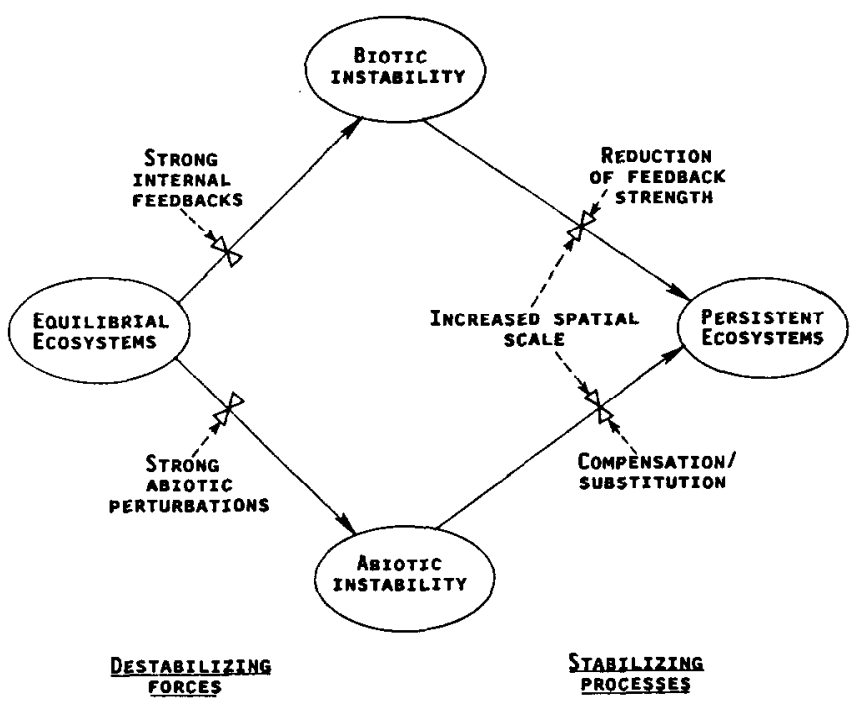

Fig. 3. Factors promoting destabilization and persistence of ecosystems. (Modified from DeAngelis and Waterhouse 1987).

instabilities in pastoral ecosystems. Why then is there such a poor record of success in the development of these ecosystems and why do degradation and famine continue in Africa? It is, in our view, because pastoral ecosystems are often strongly controlled by external forces rather than, or in addition to, internal biotic factors. Therefore the nominally applied development procedures are of ten irrelevant to the systems of interest, or worse, they comprise additional perturbations which act to further destabilize system dynamics, rather than damping them.

How does one determine whether a pastoral ecosystem is dominated by internal biotic controls or by external perturbations? Theoretical considerations and model analyses of grazing systems suggest that internal control mechanisms will come to dominate system dynamics when plant growing conditions are relatively invariant over time, whereas major variations in growing conditions will prevent the development of strong biotic interactions and feed-back controls on system dynamics (Noy-Meir 1975, Wiens 1977, 1984). A number of other structural characteristics and overall patterns of system dynamics may also be used to differentiate between equilibrial and non-equilibrial grazing systems (Table 1).

\section{Non-Equilibrial Dynamics in a Pastoral Ecosystem}

Nine years of research among pastoral nomads in northern Kenya has given us a very different view of the dynamical behavior of pastoral ecosystems than that portrayed in the equilibrial paradigm. It has also caused us to question the appropriateness of development procedures which are based on the paradigm's assumptions. The results of our work in Ngisonyoka Turkana, one of 15 sub-tribal territories in Turkana District, reveal anything but an equilibrial ecosystem. Here in the arid northwest corner of Kenya, pastoralists are locked in a constant battle against the vagaries of nature and the depredations of neighboring tribesmen. Droughts and raids are ongoing stresses; drought-induced livestock mortality frequently diminishes herds by 50 percent or more (McCabe 1985, in press, Ellis et al. 1987). Infant mortality rates are high, human nutritional status is quite dynamic, and emigration from the pastoral sector is common (Brainard 1986, Galvin 1985, McCabe 1985). However, despite the dynamic nature of the ecosystem there is little evidence of degradation or of imminent system failure (Ellis et al. 1985, Coughenour et al. 1985, McCabe and Ellis 1987). Instead, this ecosystem and its pastoral inhabitants are relatively stable in response to the major stresses on the system, e.g., frequent and severe droughts (Ellis et al. 1987). In theoretical terms this is a non-equilibrial but persistent ecosystem (Holling 
Table 1. Characteristics of equilibrial and non-equilibrial grazing systems.

\begin{tabular}{|c|c|c|}
\hline & $\begin{array}{l}\text { Equilibrial Grazing } \\
\text { Systems }\end{array}$ & $\begin{array}{c}\text { Non-equilibrial Grazing } \\
\text { Systems }\end{array}$ \\
\hline \multirow[t]{2}{*}{$\begin{array}{l}\text { Abiotic } \\
\text { Patterns }\end{array}$} & $\begin{array}{l}\text { Abiotic conditions } \\
\text { relatively constant }\end{array}$ & $\begin{array}{c}\text { Stochastic/ variable } \\
\text { conditions }\end{array}$ \\
\hline & $\begin{array}{l}\text { Plant growing } \\
\text { conditions relatively } \\
\text { invariant }\end{array}$ & $\begin{array}{l}\text { Variable plant growing } \\
\text { conditions }\end{array}$ \\
\hline \multirow{3}{*}{$\begin{array}{l}\text { Plant- } \\
\text { Herbivore } \\
\text { Interactions }\end{array}$} & $\begin{array}{l}\text { Tight coupling of } \\
\text { interactions }\end{array}$ & $\begin{array}{l}\text { Weak coupling of } \\
\text { interactions }\end{array}$ \\
\hline & Feedback control & Abiotic control \\
\hline & $\begin{array}{l}\text { Herbivore control of } \\
\text { plant biomass }\end{array}$ & $\begin{array}{l}\text { Plant biomass } \\
\text { abiotically controlled }\end{array}$ \\
\hline \multirow{3}{*}{$\begin{array}{l}\text { Population } \\
\text { Patterns }\end{array}$} & Density dependence & Density independence \\
\hline & $\begin{array}{l}\text { Populations track } \\
\text { carrying capacity }\end{array}$ & $\begin{array}{l}\text { Carrying capacity too } \\
\text { dynamic for close } \\
\text { population tracking }\end{array}$ \\
\hline & Limit cycles & $\begin{array}{l}\text { Abiotically driven } \\
\text { cycles }\end{array}$ \\
\hline \multirow{3}{*}{$\begin{array}{l}\text { Community/ } \\
\text { Ecosystem } \\
\text { Character- } \\
\text { istics }\end{array}$} & $\begin{array}{l}\text { Competitive struct- } \\
\text { ing of communities }\end{array}$ & $\begin{array}{l}\text { Competition not } \\
\text { expressed }\end{array}$ \\
\hline & Limited spatial extent & Spatially extensive \\
\hline & Self-controlled systems & $\begin{array}{l}\text { Externalities critical to } \\
\text { system dynamics }\end{array}$ \\
\hline
\end{tabular}

1973, DeAngelis and Waterhouse 1987). Our results do not support the dominant paradigm, and they demonstrate that at least for some pastoral ecosystems, the assumptions of equilibrial dynamics, and the intervention practices which follow, are inappropriate.

Climatic Variation and Plant Production in Ngisonyoka, Turkana

A critical assumption about equilibrial grazing systems is that plant growing conditions are relatively invariant over time. NoyMeir (1975) studied the stability properties of potentially equilibrial model grazing systems. His assumptions about the characteristics leading to equilibrium included time invariant growth during the growing season and no use of the forage resource outside of the growing season. These are very restrictive assumptions indeed and would not be expected to be met in many grazing ecosystems. It is probable, however, that such restrictive assumptions are not necessary for equilibrium dynamics to prevail. Equilibrium is probably possible or at least approachable in systems which demonstrate intraseasonal and intra-annual variation in plant growth provided the level of interannual variation is not too great. If the timing and magnitude of primary production is more or less predictable on an annual basis, a more or less constant carrying capacity develops and density dependent population processes permit the herbivore community to track gradual changes in the forage resource.

Pastoralists generally occupy arid or semi-arid environments where climatic variability causes distinct pulses of plant production followed by long periods of plant dormancy, but in which the pulses of production are not predictable in terms of time or magnitude. Rainfall averages between $200 \mathrm{~mm}$ and $600 \mathrm{~mm}$ over most of Ngisonyoka territory. The growing season ranges from 60 to 90 days (April-June) during normal years, leaving a 9-10 month dry season with little or no plant growth. Occasional good years occur when a short rainy period interrupts the dry season in October or November, causing another 20-30 days of plant growth. Satellite derived normalized vegetation index values (NDVI's) suggest that in the most productive regions of Turkana District, green plant biomass increases by $2-2.5$ times during the growing season, relative to the long dry season (Fig. 4). Intra-annual growing conditions are highly variable even during the best of years and are not

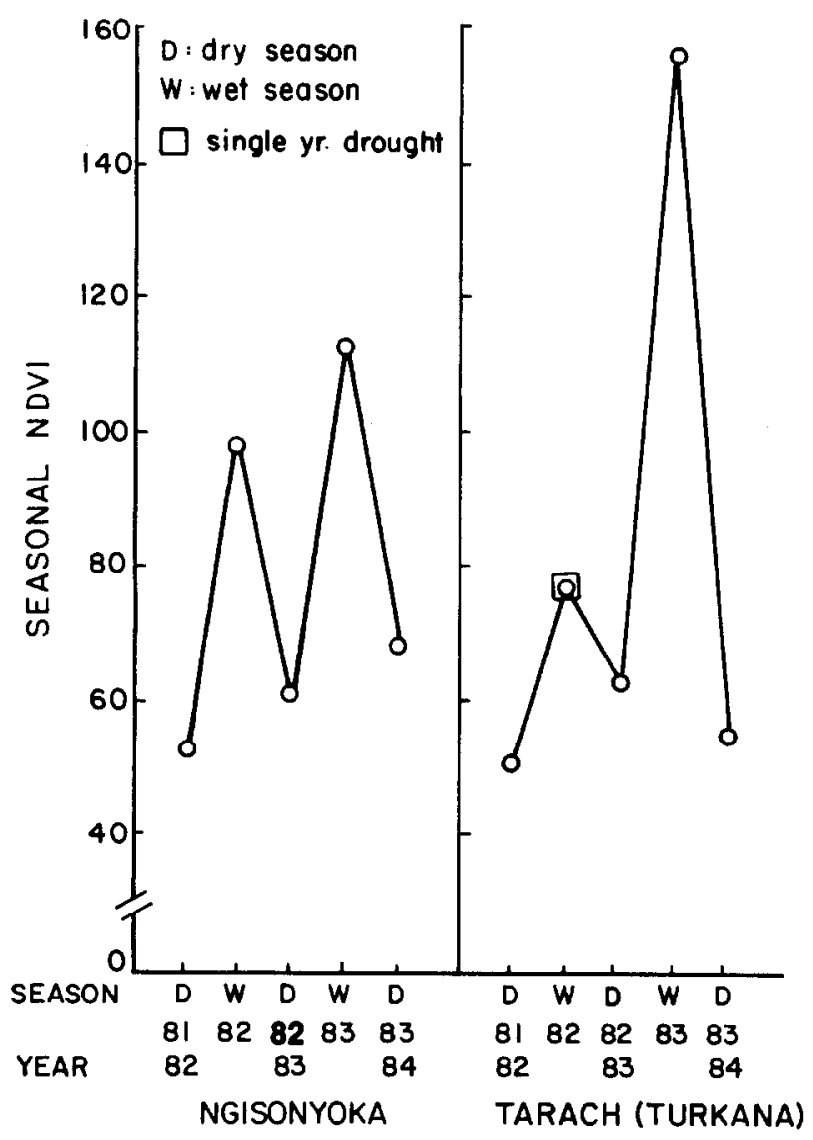

Fig. 4. Seasonal and annual NDVI dynamics.

indicative of equilibrial dynamics.

The major perturbations on the Turkana ecosystem are droughts of a year's duration or longer. In central Turkana, rainfall has dropped $33 \%$ or more below the long-term averages 13 times in the last 50 years, i.e., once every 3-4 years, and at least 4 of these have been severe multi-year droughts (Ellis et al. 1987). NDVI values recorded during a single-year drought show growing season values that are only 1-1.5 times those of the preceding dry season, indicating that plant biomass production was one-half or less of that achieved in a normal year (Fig. 4). This value may be even lower in the second year of a multi-year drought; production levels are known to drop to $1 / 3$ or $1 / 4$ of average values during droughts in some arid areas (Paulsen and Ares 1961). The dramatic response of plant biomass to dry seasons and drought demonstrates the pervasive role of climate in the vegetation dynamics of this ecosystem. The high degree of seasonality plus the great interannual variability lead to pulsed and undependable plant growth, rather than the constant or at least predictable growing conditions necessary for the development of equilibrial grazing interactions.

\section{Herbivory and Plant Production}

Another fundamental assumption about the operation of equilibrial grazing systems is that herbivores play a major role in controlling plant biomass through consumption and offtake (NoyMeir 1975, McNaughton 1979). Using ecosystem-wide estimates of forage production and livestock consumption, we calculated that total livestock offtake is on the order of $10-12 \%$ of forage production during a good year in Ngisonyoka, Turkana. Likewise, Ngisonyoka stocking rates are less than one-fourth the theoretical maximum carrying capacity in a good year, allowing for $50 \%$ forage consumption (Coughenour et al. 1985, Ellis et al. 1987). Given these stocking levels and offtake rates it seems unlikely that livestock exert a major control on plant biomass. 
Field and laboratory assessments of livestock grazing effects on herbaceous and dwarf shrub vegetation have revealed no significant grazing effects on plant production (Bamberg 1986, Coughenour et al. in prep). On the other hand, livestock do influence the morphology of important dwarf shrubs (Bamberg 1986, Mugambi in progress) and increase germination and establishment of important trees (Ellis et al. in prep, Reid in progress). Thus, while livestock may, in the long-run, alter the structure and composition of the plant community, they appear to have no role in regulating yearly plant production, only a minor role in regulating biomass levels and consequently little or no role in regulating the amount of forage available. The strong force exerted by climate on forage production and the minimal influence of livestock on forage availability means that there is little opportunity for the development of strong feedbacks from livestock to plants. The plantherbivore interaction is therefore only loosely coupled in this respect, and probably operates as a density-independent relationship most of the time. This form of interaction is indicative of non-equilibrial systems, and is inconsistent with the characteristics of equilibrial grazing systems (DeAngelis and Waterhouse 1987).

\section{Llvestock Dynamics}

Despite the fact that Ngisonyoka livestock consume only a small proportion of the total forage produced in a good year, livestock nutritional status and production rates closely track the seasonal dynamics of plant production. This is because nutritional condition and secondary production are limited by forage quality (protein content and digestibility) during the long dry seasons even though forage quantity is usually adequate. For most livestock species, diet quality drops to maintenance levels by the mid-dry season (Fig. 5), and loss of condition and reduction of production continue for several months, until the following rainy season. Though camels are able to do better than the other species, maintaining a diet of adequate nitrogen content, the digestibility of their diet declines to the point that their nutritional state is compromised also (Coppock et al. 1982, 1985, 1986a,b,c).

In drought years forage quantity as well as quality becomes limiting. While the quantity of forage removed by livestock is only moderate, that removal plus consumption by termites and losses due to decomposition and weathering eventually deplete the forage supply. During droughts, livestock are on starvation rations; nutritional condition and production spiral downward. Only the length of the drought determines how serious the effects on livestock condition and subsequently human nutrition, will be (Coppock et al. 1986b, c; Ellis et al. 1987). If droughts last two years or more, the decrements in livestock condition also begin to influence livestock population size through effects on reproduction and mortality.

We do not propose that there is no connection between livestock density and the degree of nutritional stress experienced during the annual dry period or during more extended droughts. Any time a forage resource varies in quality, there is an opportunity for density dependence to operate through competition for small quantities of the best available forage (Hobbs and Swift 1985). Thus, there is the potential for density dependent condition change during the dry season. In the case of longer droughts, it could be argued that a lower stocking rate prior to the drought results in a greater quantity of cured forage to carry the animals through the period of stress. This is correct to a point but termites, microbes, and abiotic factors deplete this resource regardless of the density of grazing animals. In the case of either seasonal dry periods or longer droughts there is simply no forage available that will maintain animals in positive nitrogen and energy balance (Coppock et al. $1986 \mathrm{c}$ ). Once the forages cure, the animals have begun the process of starvation; and the length of time that the stress must be endured is more critical to the outcome than the number of animals enduring the stress. A similar conclusion was reached by Wallmo et al. (1977) regarding the carrying capacity of mule deer winter range. While density has a role, it is small compared to the role of environmental uncertainty.

Equilibrial grazing systems exhibit strong density-dependent a)
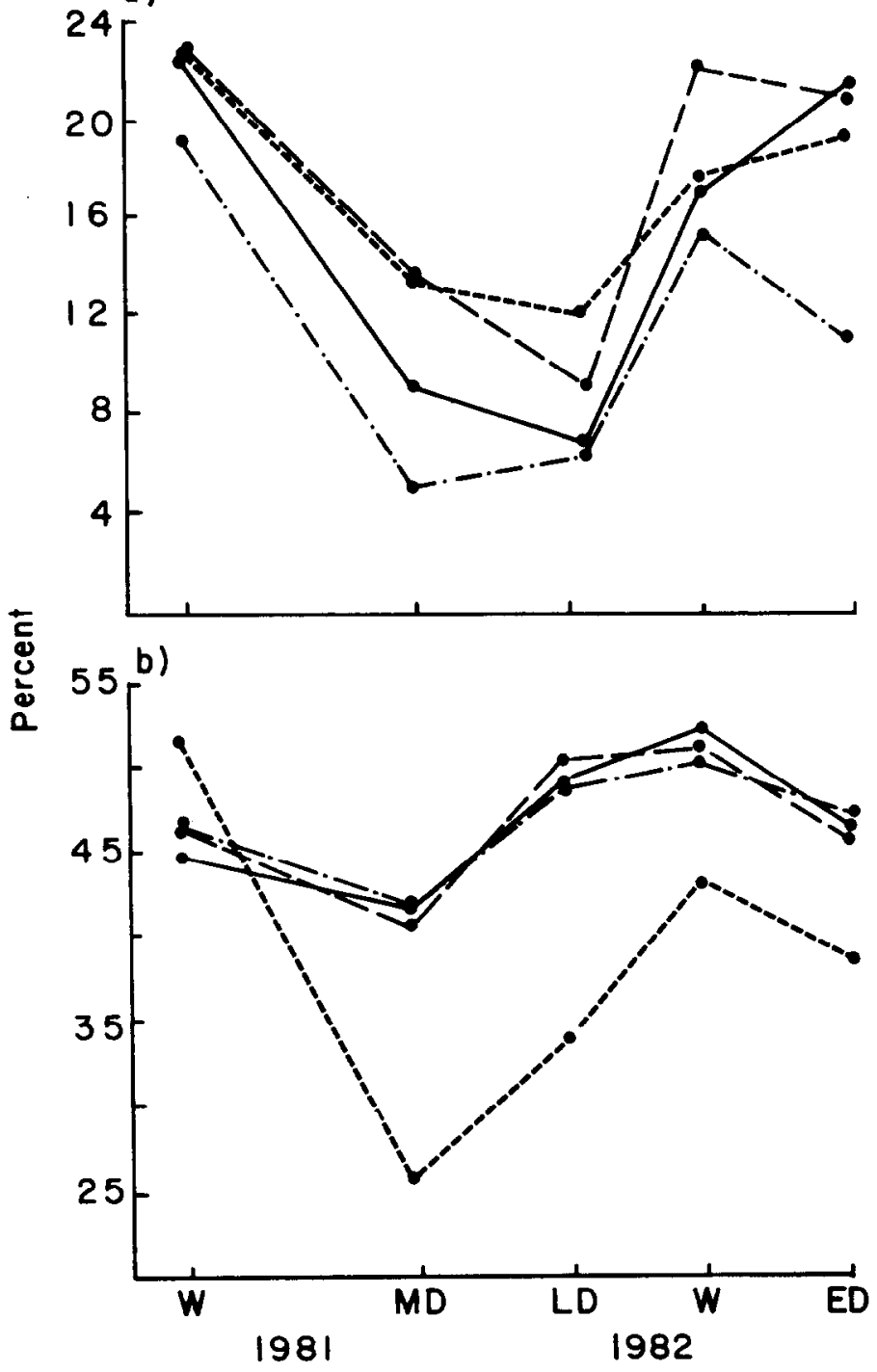

Season

Fig. 5. Seasonal concentrations for (a) crude protein, (b) IVDDM (in vitro digeatible dry matter) for livestock diets in South Turkana, Kenya, during 1981-82. Species coded as goats (- -- ), sheep ((-- -), and camels (-). Seasons are coded as W (wet, April-May), ED (early dry, June-July), MD (mid-dry, August-October), and LD (hatedry, November-March). All values are besed on $100 \%$ dry matter. (modified from Coppock et al. 1986b).

population interactions in which livestock numbers are controlled by forage availability (Noy-Meir 1975). But in Turkana, drought perturbations appear to regulate livestock populations and this control operates independent of livestock density under most circumstances. Single-year droughts undermine livestock condition and may reduce reproductive rates but do not induce livestock mortality at low to moderate stocking rates. However, even at low stocking rates, multi-year droughts cause drastic increases in livestock mortality and reductions in reproduction. A two-year drought in 1979-80 caused losses of 50-70\% of the livestock population in parts of Turkana District. But recovery from these losses was, in many cases, relatively rapid; some herds had returned to pre-drought levels four years after the drought ended. This rapid rate of recovery was largely the result of two mechanisms: rapid reproductive rates of small stock (goats and sheep) and immigration of cattle into the District after the drought ceased. Much of this immigration involved the return of animals which had been taken out of the region during the drought, while other recruitment was likely the result of raids on neighboring tribes (McCabe 1985, 


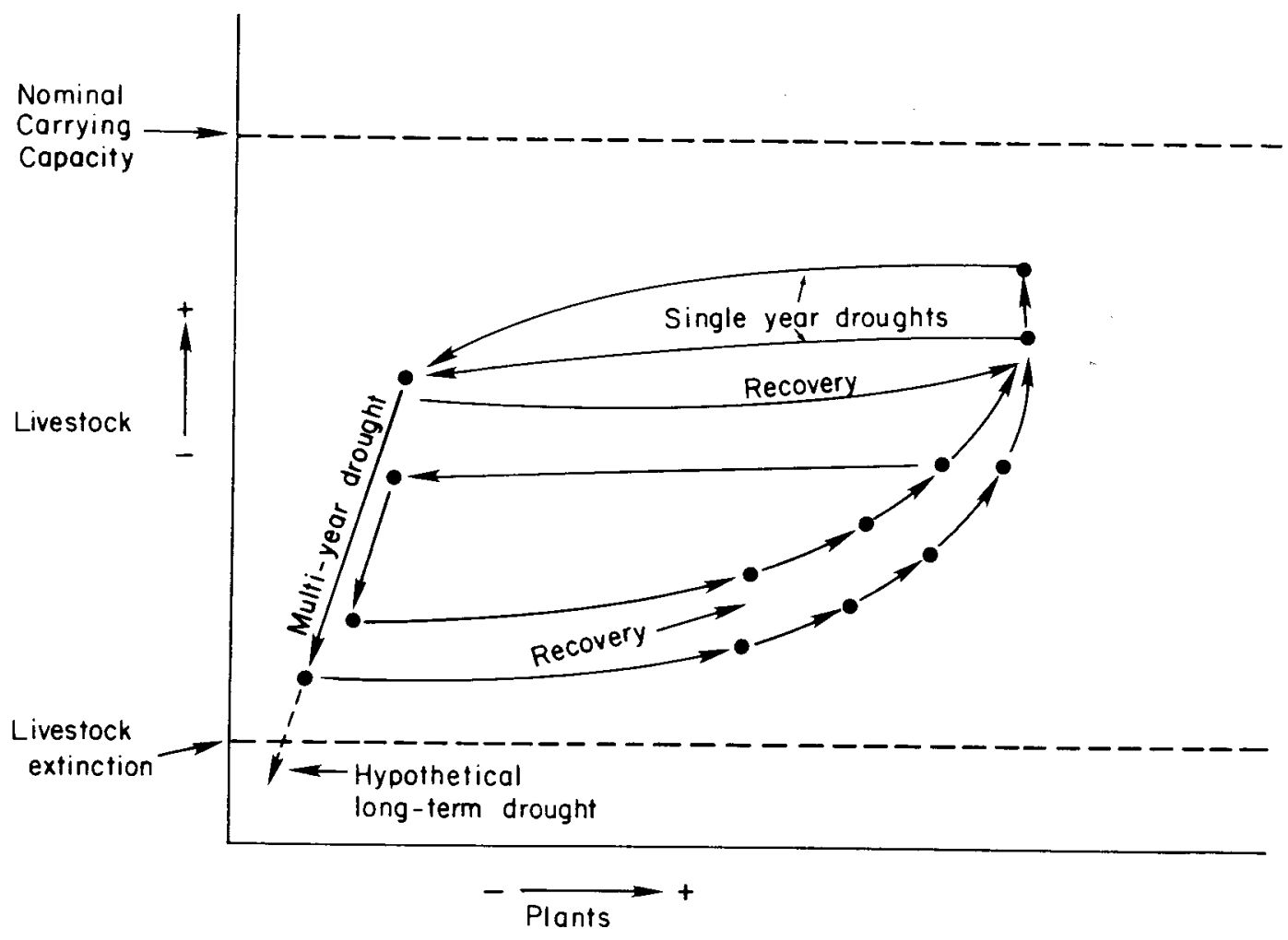

Fig. 6. Turkana plant-livestock interactions under the influence of frequent drought perturbations.

in press, Ecosystems Ltd. 1984, Ellis et al. 1987).

Livestock population dynamics in most portions of Turkana probably operate in a density-independent fashion most of the time. However, where stocking rates are relatively high, there is evidence of density-related mortality. In one small region of the District, Ngiboceros, stocking rates were about three times as high as in Ngisonyoka territory where stocking rates were only about $25 \%$ of the maximum "safe" level, based on consumption of $50 \%$ of forage. Ngiboceros stocking rates were about $75 \%$ of this maximum "safe" level. While there was no evidence of elevated mortality rates during dry seasons or single-year droughts in Ngisonyoka territory (or most of the rest of the District), Ngiboceros livestock did experience elevated mortality rates during dry seasons in nondrought years and during a single-year drought in 1984 (Ellis et al. 1987). Thus, density-related mortality occurs in Turkana, but appears to be exceptional because stocking rates seldom reach the levels required for this type of interaction to take place.

These observations suggest that Turkana livestock populations and vegetation interact as illustrated in Figure 6. During sequences of good years livestock populations expand at moderate rates. Single-year droughts have only limited effects on this pattern of increase; so based on the climatic patterns of the last 50 years, we might expect populations to continue to build between severe multi-year droughts, which have occurred about once per decade. These multi-year droughts cause population plunges, the magnitude of which may depend only weakly upon the levels of density reached prior to the drought. Between droughts, livestock populations tend toward but never reach the "nominal" carrying capacity of the vegetation, because of the relatively high frequency of multiyear drought perturbations. As a result, strong negative feedback relationships between plants and herbivores never develop. These negative feedbacks are necessary to the development of equilibrial systems and are the basis of traditional stocking rate determinations. Likewise, livestock populations approach but never reach extinction, because droughts do not last long enough to completely eliminate the livestock. The system is thus persistent in that it operates within a limited range of variation, although populations are unstable over time. This view of plant/herbivore interactions in unpredictable, arid systems is consistent with the "autecological hypothesis" of system regulation proposed by Noy-Meir (1979/80), which suggests that arid systems may be structured more by the responses of individual species to stress than by interactions among species.

\section{Human-Livestock Interactions}

Although herbivore stocking rates in Ngisonyoka are low, human density is relatively high (Ecosystems Ltd. 1984), resulting in only about 2.5 tropical livestock units per person (one TLU $=250$ $\mathrm{kg}$ ). This indicates that the human population may be near the carrying capacity of the livestock population and that the humanlivestock interaction is much more closely coupled than the plantlivestock interaction. There are significant feedback controls from humans to livestock recruitment, since pastoralists compete with calves, kids, lambs etc. for milk (Donaldson 1986). It is usually assumed that pastoralists consume about $50 \%$ of the milk produced since they milk one side of the udder and leave the other for the calf. Empirical evidence suggests that human offtake may actually be considerably higher, leaving the offspring with a much reduced quantity of milk (Donaldson 1986). Lower human offtake would almost certainly result in greater survivability and better growth rates for immature livestock. Nevertheless, Ngisonyoka husbandry allows for moderate herd growth during good years. The primary control of livestock populations still appears to be the drought perturbations which periodically reduce herds by half or more. Because the Ngisonyoka are so dependent on their livestock, such losses comprise a severe stress to the pastoralists; they must resort to extreme measures to cope with these perturbations.

\section{Pastoral Persistence}

There is clear evidence that, like the plant-livestock system, the Ngisonyoka human population is persistent. The Turkana have occupied their present region since they descended into the Rift Valley from Uganda 150 to 200 years ago (Lamphere 1976), dem- 
onstrating long-term persistence in a difficult environment. Over the past decade, which included a serious drought in 1979-80 and a single-year drought in 1984, there has been no famine in Ngisonyoka territory and no overt evidence of environmental degradation (Ellis et al. 1984, 1987). Short-term persistence was maintained despite large-scale livestock losses in a situation in which $80 \%$ of pastoral food intake is derived directly from livestock products (Galvin 1985, Galvin and Waweru 1987).

Pastoral persistence in this ecosystem is achieved through a series of stabilizing strategies which vary with the strength of the environmental stress. Dry season decrements in forage availability and livestock production are mild stresses; the Ngisonyoka compensate for dry season diminution in livestock products by switching foods and by reducing their own activity levels and energy requirements. Nevertheless, dry seasons regularly result in small declines in human nutritional status and weight, averaging 3-4\% of total body weight (Galvin 1985, Galvin and Waweru 1987). Likewise, there are indications of seasonality in human reproductive patterns with the majority of children born in the wet season, indicating that most conceptions occur when women reach their peak nutritional status in June and July (Leslie and Fry 1988).

Single-year droughts are only slightly more stressful than normal dry seasons for the Ngisonyoka; that is, the strategies employed to cope with a normal dry season are usually adequate for dealing with those relatively harsh dry seasons which follow a poor rainy season. Multi-year droughts provide a much more formidable stress and require more drastic responses. These generally take one of two forms: (1) expansion of the spatial scale of exploitation, or (2) compensation for losses of livestock products by wholesale food substitution or reduction in human demand.

\section{Expansion of the Spatial Scale of Exploitation}

Ngisonyoka territory covers about $9,000 \mathrm{~km}^{2}$. In normal years only a portion of this territory is utilized by the pastoralists and their livestock (Ecosystems Ltd. 1984, McCabe 1985); however, during severe droughts the spatial scale of exploitation expands. This is accomplished through a variety of tactics, each of which entails increasing levels of risk.

As environmental stress increases, pastoralists divide their livestock herds and and accompanying human groups into smaller and smaller units. These small units tend also to move more frequently than do the larger units which exist during wetter periods (McCabe 1985 , in press). Dispersion of the livestock and human population is facilitated by a widely distributed water supply; few large portions of the ecosystem are unusable because of lack of dry-season water (Dyson-Hudson and McCabe 1983). Division into smaller, more dispersed groups is referred to as "risk spreading" in the literature (den Boer 1968); however, smaller groups of pastoralists are actually more vulnerable to raids by bandits or other tribes, therefore incurring somewhat more risk. The real value of this dispersion is to spread grazing pressure more broadly and evenly over the region.

The fact that the Ngisonyoka have unused space to move into during periods of drought stress suggests that the system is stocked well below its average ecological carrying capacity. This is true and it is a critically important feature of the system; but not for the usual density-related reason that stocking too close to carrying capacity creates the risk of overgrazing and subsequent range degradation. In this case, the low level of stocking buys, not protection for the plant resource, but time for the pastoralist in the form of an ungrazed reserve. A single year drought is thus survivable. Large scale herd losses are avoided if the rains return before a second year of drought is encountered.

In some cases it is possible to move livestock completely out of the territory, into regions occupied by other tribes or into other subsections of Turkana, if the other pastoralists are agreeable. This tactic is especially useful if the other regions have been less affected by the impinging drought. If access to external grazing lands is not permitted, it may be necessary to move into boundary areas or "no man's lands" where the risk of intertribal raiding is especially high. Alternately, access to other tribes'resources is sometimes obtained by force, usually a difficult and bloody task (McCabe 1985, in press, Dyson-Hudson and McCabe 1983, McCabe and Ellis 1987, Ellis et al. 1987). Thus, a major strategy for coping with severe drought is to utilize fully the extensive scale of the ecosystem, or to obtain resources which are actually outside that system.

\section{Compensation for Reductions in Livestock Production}

The other major strategy for dealing with severe stress is compensation for reduction in livestock products, accomplished either by substituting other products which are available, or by reducing human demand. Alternative food products may include foods gathered from the bush; purchased foods, usually grain, obtained by selling livestock; meat from livestock which have died from starvation or disease: and relief foods, if these are available (Galvin 1985, Galvin and Waweru 1987, Ellis et al. 1987).

Reduction in human demand entails people actually leaving the pastoral system. During the multi-year drought of 1979-80, many Turkana pastoralists left the system temporarily by moving to villages or famine camps within Turkana or to highland areas where they stayed with friends or relatives or became laborers on farms, in abbatoirs, etc. (McCabe 1985). As much as $20 \%$ of the Turkana pastoral population may have emigrated from the pastoral sector in the early 1980's although many had returned by 1984 (Ecosystems Ltd. 1984). Individuals undertaking such temporary emigrations are usually of lower social status and not essential for the maintenance of pastoral herds, e.g., unmarried or widowed female relatives, young men who are not herders, etc. Their emigration does not substantially inhibit the normal functions of the system.

This combination of stabilizing strategies-food substitution, demand reduction through emigration, and expansion of the spatial scale of exploitation-allow the Ngisonyoka to persist through periods of severe stress without famine, without degrading their ecosystem, and without permanently reducing their own population. Each of these strategies depends to some extent on utilizing resources which are not exploited during non-stress periods and which lie outside the spatial scale of routine exploitation. It can be concluded that this ecosystem cannot and does not support the extant populations of humans and livestock during periods of severe environmental stress which occur about once per decade (10\%-20\% of the time). If external/peripheral resources were not available, the human and livestock populations would have to be maintained at considerably lower levels the remaining $80-90 \%$ of the time to avoid excessive livestock losses and human famine, during droughts. The ecosystem is not balanced, does not operate in an equilibrial fashion, and cannot be treated as if it did.

\section{Implications for Development}

The dominant paradigm assumes that pastoral ecosystems are potentially equilibrial grazing systems and that destabilization of these systems is due to overstocking and overgrazing by pastoralists. Conventional development practices are based on these assumptions; the goals include restoration of equilibrial conditions and increases in productivity. Conventional development procedures involve the establishment of group ranches, grazing blocks, or grazing associations where pastoralists are confined to particular tracts of land. Resources are developed and technical interventions are provided within those tracts to raise productivity and to better regulate the interaction between animals and plants. In theory these interventions have the potential to achieve the desired effects if, in fact, the problem is properly diagnosed; that is if they are applied in ecosystems which have the potential to operate as equilibrial systems, and which have truly been destabilized by overgrazing.

We have attempted to show that in Ngisonyoka Turkana and most probably in many other arid or semi-arid pastoral ecosys- 
tems, equilibrial conditions are not attainable. Rather, ecosystem dynamics are dominated by the stochastic perturbations of multiyear droughts. Under these conditions large-scale destocking would result in immediate deprivation for pastoralists even during mild stress periods. Likewise, confining pastoralists to grazing blocks or ranches would reduce the spatial scale of exploitation and result in disaster during serious droughts. The obvious conclusion is that conventional development procedures are destabilizing influences in ecosystems which are dominated by stochastic abiotic perturbations and which operate essentially as non-equilibrial ecosystems.

Can non-equilibrial pastoral systems be improved by development interventions? Or should pastoralists living under these conditions be left alone? In our view the latter is not an option. Pastoralists are coming under the influence of external forces regardless of their remoteness or of the relative success or failure of their traditional exploitation systems. Therefore we must explore the appropriateness of different development interventions for different ecosystems and design interventions to fit the dynamics of specific target systems. A cautious approach to pastoral development is to ask if intervention strategies can be formulated which will build upon the best aspects of traditional systems, rather than imposing wholesale alterations upon them.

The Ngisonyoka and several other Turkana groups seem adept at resisting the affects of severe droughts and at maintaining a sustainable and persistent, albeit unstable and dynamic, exploitation system. Their main strategies for maintaining this system in the face of perturbations are:

- expanding the spatial scale of exploitation during stress periods;

and

- compensating for productivity losses by product substitution and adjusting for loss by demand reduction.

Since these practices are key to pastoral success and persistence in non-equilibrial systems, interventions which facilitate rather than constrain these strategies should be considered. In the first case, it is clear that an extensive spatial scale is a prerequisite for a successful pastoral system where droughts are frequent. Reductions in scale or confining pastoralists to ranches is an invitation to disaster. There is no inherent reason why the maintenance of spatial scale could not be included as a development objective. However, development schemes often emphasize the delivery of "technical packages" and the improvement of resources within "tractable" areas and consider such issues as spatial scale beyond their purview.

In regard to the second strategy, food substitution and demand reduction can best be facilitated by maintaining an open economy in which there is a free flow of goods both in and out. Developing strong interactions with the national economy through viable marketing systems seems the best way to assure this flow. Improved economic flows could eventually reduce the necessary spatial scale, if the commodity flows included supplemental livestock feeds. However, these flows depend upon well-developed market and credit systems at local, regional, and national levels.

These development procedures, maintaining the spatial scale of pastoral ecosystems and facilitating the flow of goods into and out of the ecosystem through market development, are policy-oriented, rather than technical solutions. This is not to say that technical procedures are not useful; it simply suggests that they must be imbedded in a progressive pastoral development policy in order to be effective. Policy implementation is usually a national function, therefore, successful pastoral development probably can not be divorced from on-going national development. This suggests that we may need more emphasis and research on pastoral development policy and how best to use technical interventions to augment those policies, rather than emphasizing technical interventions alone, and ignoring policy-level concerns.

Should range ecologists and managers be involved in policy analysis and application as well as providing expertise on more technical issues? The main message which we wish to convey here is that appropriate policies and technical interventions can be applied only if the fundamental dynamics of the target systems are clearly understood. No one is better qualified than range ecologists to analyze and describe the dynamics of pastoral ecosystems and through this activity to provide the basic understanding necessary for enlightened development policy and intervention. Unless pastoral ecosystem dynamics are considered and used as guidelines for development policies, interventions are likely to be random activities which comprise development by trial and error, a practice with unfortunate implications for the ecosystems and people on which these "development experiments" are performed.

\section{Acknowledgments}

The research upon which this paper is based was supported by grants from the US National Science Foundation, Ecosystems Studies and Anthropology programs. Additional funding was provided by the Norwegian Aid Agency for International Development (NORAD). Our thanks to Jesse Logan, John Wiens, and Mike Coughenour for comments on the paper and to Sharren Sund for help with the manuscript.

\section{Literature Cited}

Bamberg, I.A. 1986. Effects of clipping and watering frequency on production of the African dwarf shrub Indigofera spinosa. M.S. Thesis, Colorado State University, Fort Collins.

Beuchner, H.K., and H.C. Dawkins. 1961. Vegetation change induced by elephants and fire in Murchison Falls National Park, Uganda. J. Wildl. Manage. 27:36-53.

Brainard, J. 1986. Differential mortality in Turkana agriculturalists and pastoralists. Amer. J. Physical Anthro. 70(4):525-536.

Brown, L.H. 1971. The biology of pastoral man as a factor in conservation. Biol. Conserv. 3(2):93-100.

Caswell, H. 1978. Predator mediated coexistence: a non-equilibrium model. Amer. Nat. 112:127-154.

Caughley, G. 1976. The elephant problem-an alternative hypothesis. E. Afr. Wildl. J. 14:265-283.

Charney, J.G., P.H.Stone, and W.J. Quirk. 1975. Drought in the Sahara: a biophysical feedback mechanism. Science 187:434-435.

Connell, J.H., and W.P. Sousa. 1983. On the evidence needed to judge ecological stability or persistence. Amer. Nat. 121:789-824.

Coppock, D.L., J.E. Ellis, J. Wienpahl, J.T. McCabe, D.M. Swift, and K.A. Galvin. 1982. A review of livestock studies of the South Turkana Ecosystem Project. pp. 168-172. In: Proceedings, Small Ruminant CRSP Workshop, Kenya. SR-CRSP, Nairobi.

Coppock, D.L., J.T. McCabe, J.E. Ellis, K.A. Galvin, and D.M. Swift. 1985. Traditional tactics of resource exploitation and allocation among nomads in an arid African environment. In: Proceedings of the International Rangeland Development Symposium, Society for Range Management, Salt Lake City, Utah.

Coppock, D.L., J.E. Ellis, and D.M. Swift. 1986s. Livestock feeding ecology and resource utilization in a nomadic pastoral ecosystem. $J$. Appl. Ecol. 23(2):573-583.

Coppock, D.L., D.M. Swift, and J.E. Ellis. 1986b. Seasonal nutritional characteristics of livestock diets in a nomadic pastoral ecosystem. J. Appl. Ecol. 23(2):585-595.

Coppock, D.L., D.M. Swift, J.E. Ellis, and K. Galvin. 1986c. Seasonal patterns of energy allocation and production for livestock in a nomadic pastoral ecosystem. J. Agr. Sci., Camb. 107:347-365.

Coughenour, M.B., J.E. Ellis, D.M. Swift, D.L. Coppock, K. Galvin, J.T. MeCabe, and T.C. Hart. 1985. Energy extraction and use in a nomadic pastoral ecosystem. Science 20:619-625.

Coughenour, M.B., D.L. Coppock, J.E. Ellis, and M. Rowland. Herbaceous biomass and productivity in an arid pastoral ecosystem in Northwest Kenya (in prep.).

Coughenour, M.B., D.L. Coppock, M. Rowland, and J.E. Ellis. Dwarf shrub (Indigofera spp.) ecology in South Turkana, Kenya. (in prep.)

DeAngelis, D.L., and J.C. Waterhouse. 1987. Equilibrium and nonequilibrium concepts in ecological models. Ecol. Monogr. 57(1):1-21.

denBoer, P.J. 1968. Spreading the risk and stabilization of animal numbers. Acta Biotheoretica (Leiden) 18:165-194. 
Dublin, H. 1987. Decline of the Mara woodlands: the role of fire and elephants. Ph.D. Thesis, University of British Columbia.

Dyson-Hudson, R., and J.T. McCabe. 1983. Final Report to the Norwegian Aid Agency on South Turkana Water Resources and Livestock Management.

Donaldson, T.J. 1986. Pastoralism and drought: a case study of the Borana of southern Ethiopia. M. Phil Thesis, University of Reading.

Ecosystems, Ltd. 1984. Turkana District resource survey. Turkana Rehabilitation Project, Draft Final Report, July 1984. Ministry of Energy and Regional Development, Government of Kenya, Nairobi.

Ellis, J.E., D.L. Coppock, J.T. McCabe, K. Galvin, and J. Wienpahl. 1984. Aspects of energy consumption in a pastoral ecosystem: wood use by the southern Turkana. In: C. Barnes, J. Ensminger and P. O'Keefe, (eds.) Wood, Energy and Households, Perspectives on Rural Kenya. Energy, Environment and Development in Africa (6). The Beijer Institute and the Scandinavian Institute of African Studies, Sweden.

Ellis, J.E., D.S. Schimel, M.B. Coughenour, T.C. Hart, J.G. Wyant, and S. Lewis. Enhancement of tree establishment by pastoral nomads in an arid tropical ecosystem. (in prep.).

Ellis, J.E., K. Galvin, J.T. McCabe, D.M. Swift. 1987. Pastoralism and drought in Turkana District, Kenya. A report to NORAD, Nairobi. $204 p p$.

Evans-Pritchard, E.E. 1973. The Nuer. Oxford University Press, London.

Galvin, K.A. 1985. Food procurement, diet and nutrition of Turkana pastoralists in the ecological and social context. Ph.D. Diss. State University of New York, Binghamton.

Galvin, K., and S.K. Waweru. 1987. Variation in the energy and protein content of milk consumed by nomadic pastoralists of northwest Kenya. In: A.A.J. Hansen, H.T. Horelli and V.J. Quinn (eds.) Food and Nutrition in Kenya. A Historical Review, UNICEF, Nairobi.

Glover, J. 1963. The elephant problem at Tsavo. E. Afr. Wildl. J. 1:30-39.

Hardin, G. 1968. The tragedy of the commons. Science 162:1243-48.

Helland, J. 1980. Five Essays on the Study of Pastoralists and the Development of Pastoralism. Occasional paper No. 20. Sosialanthropologisk Institut, Universitetet i Bergen, Bergen, Norway.

Herskovits, M.J. 1926. The cattle complex in East Africa. American Anthropologist Vol. 28.

Hobbs, N.T., and D.M. Swift. 1985. Estimates of habitat carrying capacity incorporating explicit nutritional constraints. J. Wildl. Manage. 49:814-822.

Holling, C.S. 1973. Resilience and stability of ecological systems. Ann. Rev. Ecol. Syst. 4:1-23.

ILCA (International Livestock Centre for Africa). 1987. ILCA's Strategy and Long-term Plan: A Summary. Addis Ababa, Ethiopia.

Jacobs, A.H. 1965. The traditional political organization of the pastoral Maasai. Unpublished Ph.D. Thesis, Oxford University. 427 pp.

Kuhn, T.S. 1970. The Structure of Scientific Revolutions, 2nd Ed. University of Chicago Press.

Lamphere, J. 1976. The Traditional History of the Jie. Oxford University Press, London.

Lamprey, H.F. 1983. Pastoralism yesterday and today: the overgrazing problem. pp. 643-666 In: F. Bourliere (ed.), Tropical Savannas: Ecosystems of the World, Vol. 13. Elsevier, Amsterdam.

Lamprey, H.F., and H. Yussuf. 1981. Pastoralism and desert encroachment in northern Kenya. Ambio 10:131-147.

Laws, R.M. 1970. Elephants as agents of habitat and landscape change in East Africa. Oikos 21:1-15.

Leslie, P.W., and P.H. Fry. Extreme seasonality of births among South Turkana pastoralists. (submitted).

Luaigi, W.J. 1981. Combatting Desertification and Rehabilitating Degraded Population Systems in Northern Kenya. Tech. Rep. A-4, UNESCOUNEP Integrated Project in Arid Lands, Nairobi.
McCabe, J.T. 1985. Livestock management among the Turkana: a social and ecological analysis of herding in an East African pastoral population. Ph.D. Diss. State University of New York-Binghamton.

McCabe, J.T. Drought and recovery: Livestock dynamics among the Ngisonyoka Turkana of Kenya. Human Ecology (in press).

McCabe, J.T., and J.E. Ellis. 1987. Beating the odds in arid Africa. Nat. Hist. 96(1):32-41.

Nicholson, A.J. 1958. The self-adjustment of populations to change. Cold Spring Harbor Symp. Quant. Biol. 22:153-173.

Nicholson, A.J., and V.A. Bailey. 1935. The balance of animal populations. J. Animal Ecol. 2:132-178.

Norton-Griffiths, M. 1979. The influence of grazing, browsing and fire on the vegetation dynamics of the Serengeti. In: A.R.E. Sinclair and M. Norton-Griffiths (eds.), Serengeti: Dynamics of and Ecosystem. University of Chicago Press, Chicago.

Noy-Meir, I. 1975. Stability of grazing systems: an application of predatorprey graphs. J. Ecol. 63:459-481.

Noy-Meir, I. 1979/80. Structure and function of desert ecosystems. Isr. J. Bot. 28:1-19.

Oxby, C. 1982. Group ranches in Africa. Overseas Development Institute Review. 2:2-13.

Paulsen, H.A., and F.N. Ares. 1961. Trends in carrying capacity and vegetation on arid southwestern range. J. Range Manage. 14:78-83.

Pellew, R.A. 1983. The impacts of elephant, giraffe and fire upon the Acacia tortilis woodlands of the Serengeti. Afr. J. Ecol. 21:41-74.

Rosenzweig, M.L., and R.H. MacArthur. 1963. Graphical representation and stability condition of prey-predator interactions. Amer. Nat. 97:209-223.

Sandford, S. 1983. Management of Pastoral Development in the Third World. John Wiley and Sons, New York.

Sinclair, A.R.E., and J.M. Fryxell, 1985. The Sahael o Africa: ecology of a disaster. Can. J. Zool. 63:987-994.

Spencer, P. 1973. Nomads in Alliance. Symbiosis and Growth Among the Rendille and Samburu of Kenya. Oxford University Press, London.

Stebbings, E.P. 1935. The encroaching Sahara. Geo. J. 86:510.

Stiles, D.N. 1983. Camel pastoralism and desertification in Northern Kenya. Desert. Contr. 8:2-8.

Swift, J. 1977. Pastoral development in somalia: herding cooperatives as a strategy against desertification and famine. In: M.H. Glantz (ed.), Desertification: Environmental Degradation in and Around Arid Lands, Boulder Westview Press.

Swift, J., and A. Maliki. 1984. A cooperative development experiment among nomadic herders in Niger. Overseas Development Institute, paper $18 \mathrm{c}$.

Volterra, V.1928. Variations and fluctuations of the number of individuals in animal species living together. Translated in R. N. Chapman 1931. Animal Ecology. McGraw-Hill, New York.

Wallmo, O.C., L.H. Carpenter, W.L. Regelin, R.B. Gill, and D.L. Baker. 1977. Evaluation of deer habitat on a nutritional basis. J. Range Manage. 30:122-127.

Wiens, J.A. 1977. On competition and variable environments. Amer. Sci. 65:590-597.

Wiens, J.A. 1984. On understanding a non-equilibrium world: myth and reality in community patterns and processes. In: D.R. Strong, Jr., D. Simberloff, L.G. Abele, A.B. Thistle (eds.), Ecological Communities: Conceptual Issues and the Evidence, Princeton University Press, Princeton, New Jersey.

Western, D. 1973. Structure, dynamics and changes of the Amboseli Basin ecosystem. Ph.D. Diss. Nairobi University. 